\title{
“Tá com dó? Leva pra casa!” Análise dos discursos favoráveis à redução da maioridade penal em rede social
}

\author{
Heloísa Petry \\ Universidade Federal de Santa Catarina, SC, Brasil.
}

\author{
Deise Maria do Nascimento \\ Universidade do Sul de Santa Catarina, SC, Brasil.
}

\begin{abstract}
Resumo: Pretende este artigo analisar as proposições favoráveis à redução da maioridade penal expressas em publicações de uma página virtual da rede social Facebook. Constata-se que a volúpia punitiva se expressa de maneira seletiva e hierárquica sobre determinados adolescentes, de modo que o recrudescimento da punição é concebido como estratégia de resolução a problemas sociais supostamente gerados por uma sociedade protetiva e permissiva. O estudo é orientado pelo método de análise hermenêutico-dialético que visa compreender e, ao mesmo tempo, confrontar a problemática frente às suas contradições e conflitos. A partir do diálogo entre campos de saber interdisciplinares, problematiza-se a implicação destes pressupostos acerca da redução da maioridade penal no que tange à constituição do sujeito autor de ato infracional e dos sujeitos produtores destes discursos, assim como o impacto destas afirmativas em sociedades marcadas por relações excludentes.
\end{abstract}

Palavras-chave: Maioridade Penal, Adolescentes, Ato Infracional, Redes sociais.

\section{"Do you Feel Sorry for Him? Then Take him into Your Home!" Analysis of Speeches in Favor of Reducing the Legal Age for Criminal Responsibility in a Social Network}

\begin{abstract}
This article aims to analyze the proposals in favor of reducing the legal age for criminal responsibility, expressed in publications of a virtual page of Facebook. It appears that the punitive voluptuousness is selectively and hierarchically expressed on certain teenagers, as the resurgence of punishment is designed as a solving strategy to social problems supposedly generated by a protective and permissive society. The study is guided by the hermeneutic-dialectic method which seeks to understand and, at the same time, confront this problematic in terms of its contradictions and conflicts. From a dialogue between interdisciplinary fields of knowledge, the implication of these assumptions about reducing the legal age for criminal responsibility is discussed, related to the constitution of the subject who commits an offense and of the subjects that produce these speeches, as well as the impact that these speeches have on societies marked by social exclusion.
\end{abstract}

KeYwords: Legal Age for Criminal Responsibility, Adolescents, Offense, Social Networks. 


\title{
“¿Sientes Pena por Él? ¡Pues Llévatelo para tu Casa!” Análisis de Discursos Favorables a la Reducción de la Mayoría de Edad Penal en una Red Social
}

\begin{abstract}
Resumo: Este artículo tiene como objetivo analizar las propuestas a favor de la reducción de la mayoría de edad penal expresadas en publicaciones de una página virtual de la red social Facebook. Se constata quela voluptuosidad punitiva se expresa selectivamenteyjerárquicamente sobre ciertos adolescentes, viéndose el recrudecimiento del castigo como una estrategia de resolución de problemas sociales supuestamente generados por una sociedad protectora y permisiva. El estudio se guía por el método hermenéutico-dialéctico que busca comprender y, al mismo tiempo, confrontar la problemática frente a sus contradicciones y conflictos. A partir del diálogo entre campos del conocimiento interdisciplinares, se analiza la implicación de estos presupuestos acerca de la reducción de la mayoría de edad penal, en relación con la constitución del sujeto que comete una infracción y con los sujetos que producen estos discursos, así como el impacto de estas declaraciones en sociedades marcadas por relaciones excluyentes.

Palabras clave: Mayoría de Edad Penal, Adolescentes, Crimen, Redes Sociales.
\end{abstract}

\section{Introdução}

Há mais de duas décadas tramitam proposições favoráveis acerca da temática da redução da maioridade penal, totalizando um conjunto de 22 propostas apresentadas à Câmara dos Deputados e Senado Federal (Conselho Federal de Psicologia, 2013). As estratégias de criminalização apresentadas como enfrentamento à "criminalidade juvenil" nas propostas legislativas não estão isoladas e encontram respaldo em uma parcela significativa da sociedade, conforme as últimas pesquisas de opinião disponíveis, que mostram apoio à medida em diferentes regiões do país (Confederação Nacional dos Transportes, 2013; Datafolha, 2013). Observa-se também uma considerável mobilização nas redes sociais acerca do tema, através de páginas, grupos e campanhas que ilustram a divergência de opiniões ${ }^{1}$.

A rede social Facebook é uma das mais utilizadas em todo o mundo e o Brasil é o segundo país com o maior número de usuários desta rede, perdendo apenas para os Estados Unidos (Ciriaco, 2012). O surgimento destas formas de agrupamentos via ciberespaço criam novas proposições para as relações sociais compreendidas tradicionalmente, pois a estabilidade e fixidez não se efetiva nestes espaços: os agentes sociais tornam-se instáveis e múltiplos e a veiculação constante da informação interpela esta constituição por meio da linguagem (Lyon, 1997).

Embora o presente artigo não se detenha na análise da relação entre os discursos apresentados e a rede social, é importante destacar previamente que o contexto de produção de conhecimento e circulação de ideias nestes espaços operam por outras vias, como as da informalidade e do descompromisso com a empiricidade e/ou criticidade da informação circulante. Rudiger (2002, p. 122) aponta ainda sobre a possível existência de uma expressividade menos polida nestes meios em relação a outros meios de interação social: "os contatos virtuais, senão estimulam, ensejam a certas pessoas serem mais abertamente agressivas ou menos controladas do que o são na vida cotidiana".

Partindo-se do princípio de que as construções das defesas pelo recrudescimento da punição aos adolescentes pautam-se em ideologias, a partir da concepção adotada por Chaú (1980), em que a compreensão acerca de um determinado tema está necessariamente enviesada por uma dada visão de homem - singular e universal-e de mundo, torna-se fundamental atentar-se para quais pressupostos estão sendo apresentados pelos segmentos da sociedade que apoiam tais medidas.

1. Conforme levantamento realizado no período de setembro de 2013, contabilizando-se as páginas a partir de 100 integrantes, constam: 17 páginas favoráveis à redução; 6 contrárias; 3 que propõe o debate e 2 dedicadas à campanha pela realização de plebiscito e manifestações públicas. 
Conforme dados coletados a partir do Mapa da Violência de 2012, evidencia-se o crescimento exacerbado da mortalidade de crianças e adolescentes nas últimas décadas: o Brasil ocupa a $4^{\circ}$ posição internacional dentre 99 países no índice de mortalidade de crianças e adolescentes, sendo o homicídio a principal causa destas mortes, especificamente na faixa dos 10 aos 14 anos e dos 15 aos 19 anos, conforme a Organização Mundial da Saúde (Waiselfisz, 2012). De maneira geral, considerando-se as principais vítimas da violência no país a partir deste mapa, o que se evidencia é uma mortalidade seletiva: são jovens, negros e de baixa renda - informações que raramente constam em jornais ou em notícias televisivas.

Em relação aos homicídios cometidos por adolescentes, os dados estatísticos mostram que há uma disparidade significativa entre adolescentes que morrem e adolescentes que matam. Os jovens com menos de 18 anos são responsáveis por $10 \%$ dos delitos cometidos em todo o território nacional, bem como, dentre os delitos cometidos por jovens, a maioria dos crimes são contra o patrimônio e não crimes contra a vida estes representam menos de 1,4\% (Unicef, 2007). Há, portanto, uma incongruência entre o ideário construído na mídia e na opinião pública e o que se evidencia estatisticamente: mais do que "violentadores", os adolescentes brasileiros são majoritariamente "violentados". É importante frisar que não se trata de deslocar a vitimização da "sociedade" para os adolescentes, mas de apontar que as atribuições comuns das causas da criminalidade e da identificação da violência como mal-estar a ser combatido permeiam uma representação maniqueísta da sociedade ${ }^{2}$, fomentada também pela veiculação distorcida da mídia que tem a violência como objeto de consumo (Segata, 2012).
Embora haja notoriedade acerca da redução da maioridade penal no senso comum, no meio científico as discussões ainda permanecem escassas. Destaca-se que não foram encontrados nas bases de dados BVS-Psi e portal da CAPES, construtos teóricos que abordem a presente temática utilizando-se o ciberespaço como recurso investigativo para pesquisa, o que evidencia uma lacuna importante para posteriores discussões no âmbito científico.

\section{Aportes teórico-metodológicos da pesquisa}

Objetiva-se compreender os fundamentos que sustentam as defesas à redução da maioridade penal apresentados em uma página virtual da rede social Facebook. Para isso, buscou-se identificar de que maneira os participantes da página virtual caracterizam os sujeitos que são públicos-alvo destas propostas; como compreendem o contexto concernente à "criminalidade juvenil" e, ainda, como propõem o enfrentamento a esta problemática.

Com vistas a atender aos objetivos propostos, adotou-se a perspectiva exploratória ea abordagem qualitativa no tratamento dos dados de fonte documental. Foram elencadas seis páginas ${ }^{3}$ para traçar um perfil comparativo e construir um panorama dos discursos que circulam na rede social. Dentre estas, selecionou-se apenas uma página, intitulada "Redução da Maioridade Penal Já", para servir como modelo referencial de análise para as discussões propostas a partir dos objetivos, tendo como critério de seleção uma maior dinâmica interacional desta página em relação às demais, definida pelo padrão de interatividade própria desta rede, por meio dos "3 C's: comentar, curtir e compartilhar" (Preteat, Silva, Triska, \& Schlenburg, 2012) ${ }^{4}$.

2. Entende-se por representação maniqueísta da sociedade uma compreensão dos fenômenos sociais a partir da divisão dicotômica entre bem e mal. Como definição da palavra maniqueísmo consta: “1. Fil. Doutrina do persa Mani ou Manes (séc. III) segundo a qual o mundo foi criado e é dominado por dois princípios antagônicos, o bem absoluto, que é representado por Deus, e o mal absoluto, representado pelo Diabo 2. Forma de julgamento ou de avaliação que reduz uma questão a dois aspectos opostos e incompatíveis” (Aulete Digital, 2015). 3. A seleção destas páginas foi realizada conforme maior número de "curtidas" recebidas pelas mesmas. No entanto, vale destacar que este foi apenas um critério de seleção das páginas que receberam maior notoriedade e são mais ativas, pois, curtir uma página não necessariamente significa aderir ao seu conteúdo, de modo que os usuários destas redes sociais podem dispor de inúmeras motivações para curtir uma página (querer acompanhar o que está se falando sobre, curtir porque convidaram a curtir, etc.), motivações as quais superam as possibilidades investigativas desta pesquisa.

4. A dinâmica interacional pública na rede virtual Facebook ocorre principalmente através das ações denominadas "3 C’s: comentar, curtir, compartilhar" (Preteat et al., 2012). A ação de curtir se refere à confirmação daquilo que está sendo exposto; comentar se refere à expressão de comentário acerca do que foi exposto e compartilhar diz respeito à republicação de uma determinada imagem ou texto, expandindo assim, uma publicação de uma rede para outra. Qualquer uma dessas ações é exibida para os integrantes da rede selecionados pelo usuário, sendo este "notificado" quando alguém curtiu, compartilhou ou comentou alguma de suas publicações. A página selecionada operava ativamente com estas três categorias, de modo que muitos integrantes não apenas curtiam as postagens, como também emitiam comentários e republicavam as postagens em suas páginas pessoais, expandindo assim o conteúdo da página para os seus circuitos de amizades virtuais. 
O método de análise dos dados adotado segue algumas das proposições da "hermenêutica-dialética" proposta por Minayo (1994), que parte da fala enunciada para ir em direção à especificidade histórica e totalizante produtora da fala. Considera-se nesta pesquisa como "fala" a conjuntura de escritas e imagens que compõem as postagens na rede social. Esta metodologia orientou a pesquisa principalmente pela proposta de compreensão da realidade centrada na linguagem - que deve ser sempre situada em um dado contexto histórico, político e sociocultural. Deste modo, conforme Minayo e Deslandes (2002), a análise deve instaurar a compreensão e a busca pelo sentido das falas (hermenêutica) ao mesmo tempo em que localiza os conflitos e contradições, provocando o dissenso e a ruptura do sentido (dialética).

A proposta deste método compreende dois níveis de interpretação, a saber: o das determinações fundamentais, que diz respeito ao contexto sócio-histórico do grupo pesquisado ${ }^{5}$ e o nível de encontro com os dados empíricos - neste caso, as publicações postadas na página selecionada para análise. Seguindo a metodologia citada, realizou-se a ordenação, sistematização e classificação dos dados e, por fim, a análise dos mesmos a partir de construtos teóricos que puderam auxiliar na discussão das informações encontradas.

O referencial teórico da pesquisa pauta-se na interlocução entre autores de diferentes áreas do conhecimento a fim de que possam contribuir para a problematização dos dados coletados. Embora alguns autores possam partir de perspectivas epistemológicas distintas, convergem na tradição filosófica da crítica à modernidade, na desconstrução do paradigma positivista e no diálogo com a historicidade dos fenômenos apresentados. Estando inserido no campo do conhecimento psicológico, este artigo ancora-se em autores que rompem com a noção de indivíduo como uma entidade descolada do "social", entendendo-se que este princípio - do estatuto do indivíduo - concedeu lugar à Psicologia como ciência e profissão, juntamente com seu enfoque adaptativo e normativo (Prado Filho, 2005).

\section{Análise e discussão dos resultados}

Ao investigar na página de análise as características atribuídas aos adolescentes aos quais são endereçados os argumentos favoráveis à redução da maioridade penal a partir das imagens e escritos que circulam nas publicações, constata-se que são retratados adolescentes homens, predominantemente negros e moradores de favelas, com estereótipos bastante delimitados. Sendo jovens pobres e negros o público-alvo dos enunciados da página, serão também eles o ponto de partida de toda análise.

Monta-se nesta página uma tipologia do sujeito ameaçador e potencialmente criminoso, que remetem aos pressupostos positivistas das ciências criminológicas do século XIX pautadas no paradigma etiológico que localizavam no indivíduo desviante os fatores ontológicos determinantes de sua condição de "criminoso nato". Embora apresentem novos formatos, estes pressupostos atravessam séculos de permanência tanto na ciência e no sistema penal, quanto no senso comum (Andrade, 2003). São os estudos de Lombroso (1876) e seus seguidores, os principais precursores de modelos que versam sobre o mapeamento generalizável de características físicas e psicológicas que sirvam como causa e efeito da criminalidade, sendo marcadores historicamente significativos no que se refere à legitimação da limpeza étnica e racismo no interior do sistema penal (Andrade, 2003). É também neste contexto positivista e classificatório do final do século XIX e início do século XX que "nasce" a Psicologia na condição de "ciência" em que, frente ao ajuste desta com as ciências naturais, também pôs-se a serviço da criação de leis imutáveis sobre os sujeitos (Prado Filho, 2005).

A atribuição do status de criminoso marca identidades e funda subjetividades. Foucault (2000), ao discorrer sobre a passagem dos suplícios espetaculares para a punição mais velada em sua aparência, "uma execução que atinja a vida mais do que o corpo", uma "tecnologia da alma", afirma que a atribuição do rótulo da delinquência permite "dar aos mecanismos da punição legal um poder justificável não mais simplesmente sobre as infrações, mas sobre os indivíduos; não mais sobre o que eles fizeram, mas sobre aquilo que eles são, serão ou possam ser" (Foucault, 2000, p. 20, grifo nosso).

A criminalização da pobreza mostra-se como ponto chave na compreensão da dinâmica do sistema

5. Tendo o ciberespaço como campo de investigação da pesquisa, algumas limitações se impuseram frente ao primeiro nível de interpretação desta metodologia, dificultando a caracterização do perfil dos integrantes da página, tendo em vista o tempo limitado para a pesquisa e o número de integrantes da página de 5.296 membros - contagem de junho de 2013. 
penal e da volúpia punitiva (Singer, 1998) ${ }^{6}$. Sendo a estrutura do sistema penal inoperante em toda sua extensão-pois não sendo criminalizados todos os que cometem crimes - necessariamente a criminalização ocorre de maneira desigual e seletiva, círculo ininterrupto que conduz à legitimação e naturalização da intervenção repressiva do Estado e à reprodução de estigmas e estereótipos sociais (Andrade, 2003).

Neste sentido, na página pesquisada, constam publicações que trazem o seguinte enunciado: "Parem com a hipocrisia. Não se trata disso (imagem de crianças brancas acorrentadas chorando) e sim disso (imagem de adolescentes negros com camisetas enroladas no rosto e armas na mão)" ou ainda: "crianças e adolescentes são uma coisa, MENOR MARGINAL é outra!", delimitando a seletividade punitiva entre aqueles que são denominados "crianças e adolescentes" merecedores de proteção e aqueles, rotulados de "menores infratores" e "bandidos", sujeitos à punição.

O que estes enunciados fazem, na realidade, é delatar às claras o procedimento que permeia toda a trajetória das políticas públicas da infância e adolescência no Brasil no que concerne ao tratamento legal, como a doutrina de situação irregular, por exemplo, que expunha a seletividade na letra da lei, contendo no termo "situação irregular" o equivalente à pobreza (Sandrini, 2009) ${ }^{7}$. Embora estas políticas estivessem revestidas do princípio da proteção - alicerçado na concepção de incapacidade dos menores - repetidamente e sob novas vestes, apresentaram-se majoritariamente como instrumentos de controle social de crianças e adolescentes negros e pobres (Sandrini, 2009). Ressoa historicamente, no Brasil, uma cultura autoritária e seletiva com a qual os principais operadores da legislação do Estatuto da Criança e do Adolescente (ECA) ainda não provocaram rupturas consistentes (Oliveira, 1999) ${ }^{8}$.

Quando surgem na página especulações a partir da divulgação televisiva em rede nacional acerca da suspeição de um menino ter assassinado sua família - com características bem opostas à tipologia que circula na página - os comentários gerados foram neste sentido: "com certeza não foi essa criança autora desse crime brutal" ou ainda, repensa-se inclusive a redução da maioridade penal, tão avidamente defendida por um participante muito ativo na página: "toda regra tem exceção... somente nesses casos nem se precisaria reduzir a maioridade penal [...] passaria primeiro pelo uma avaliação medica (sic): psicóloga e física” (grifo nosso).

O proposto abrandamento da punição "nesses casos" com "essas crianças" - em que a "regra" que não se aplica é supostamente a criminalização do adolescente negro da periferia - vem ratificar o que Souza (2010) denomina como "hierarquia moral" de alguns sujeitos e/ou grupos sobre outros, que, por seu caráter pré-reflexivo, está secularmente enraizada em toda a sociedade como um "fio invisível", inviabilizando a regra política e jurídica de igualdade não apenas por uma questão simplificada meramente econômica

6. O termo “volúpia punitiva” utilizado por Singer (1998) não é conceituado pela autora, todavia, ao longo de seu trabalho é possível notar que a mesma faz uso do termo "obsessão punitiva" como correlato. Em sua etimologia, volúpia relaciona-se com prazer, com deleite; porém, dentro neste contexto, não deve ser concebido como algo individualizado. Trata-se de um termo que pode ajudar a dimensionar o movimento crescente de clamor por punição, relacionado com o modelo de penalidade neoliberal (Wacquant, 2001) e da judicialização das relações sociais (Rifiotis, 2012).

7. A título de contextualização, são três as doutrinas ou teorias jurídicas no Brasil referentes à população de crianças e adolescentes: a doutrina do direito penal do menor (Código de Mello Matos de 1927, primeiro Código de Menores da América Latina, tendo oficializado a categoria "menor"), doutrina da situação irregular (1979) e doutrina da proteção integral, sendo esta última adotada na atualidade, na qual o Estatuto da Criança e do Adolescente (1990) está ancorado, excluindo a categoria menor. A doutrina da situação irregular, citada no texto, pautou-se na ideologia tutelar estatal, tendo como foco um tipo específico de adolescente, aquele que mediante verificação, constatava estar em situação irregular. Os critérios para definição desta "situação irregular" não eram objetivos, estando à mercê da definição exclusiva do juiz de menores e de sua equipe técnica (psiquiatras, psicólogos, pedagogos entre outros) apenas tornando evidente uma diferenciação de classes, delimitando na prática seletiva dos operadores jurídicos quem de fato eram os "menores" aos quais o Código estava endereçado (Sandrini, 2009).

O Estatuto da Criança e do Adolescente, ao elevar o status das crianças e adolescentes como "sujeitos de direitos", buscou romper com os vários sentidos que indicavam permissividade para intervenções, tutela e marginalização sobre os "menores", como assim eram denominados nas doutrinas anteriores, bem como a alteração do termo crime por ato infracional e pena por medida socioeducativa. A modificação dos termos, no entanto, não produziu resultados significativos, uma vez que não superaram o ideário criminalizante e repressor, tornando-se, inversamente a mudanças, apenas eufemismos (Sandrini, 2009).

8. O Estatuto da Criança e do Adolescente, ao elevar o status das crianças e adolescentes como "sujeitos de direitos", buscou romper com os vários sentidos que indicavam permissividade para intervenções, tutela e marginalização sobre os "menores", como assim eram denominados nas doutrinas anteriores, bem como a alteração do termo crime por ato infracional e pena por medida socioeducativa. A modificação dos termos, no entanto, não produziu resultados significativos, uma vez que não superaram o ideário criminalizante e repressor, tornando-se, inversamente a mudanças, apenas eufemismos (Sandrini, 2009). 
produtora da desigualdade tal como a má distribuição de renda ou de políticas sociais, mas, sobretudo, porque o valor atribuído aos seres humanos não é o mesmo: ser "gente", "ser humano" ou "cidadão" são noções social e subjetivamente construídas e apropriadas, com todas as implicações que tais valorações acarretam sobre os sujeitos.

São despejadas neste meio, inúmeras referências que expressam a desqualificação, ausência ou banimento da categoria "humano" ou "cidadão" àqueles adolescentes que na hierarquia social são reduzidos a: "lixos humanos"; "parasitas"; "monstros"; "vermes"; "selvageria"; "marginais"; "vagabundos"; numa oposição muito clara à valoração que os integrantes da página atribuem a si mesmos - "cidadãos de bem", "pais de família", "inocentes"; "trabalhadores”; "pagadores de impostos" - sobrecarregados pelo sustento de indesejáveis: "infelizmente a gente sustenta um bando de parasitas vagabundos", empecilhos que supostamente dificultam a proteção dos direitos que beneficiariam "a maioria" da população, realçando também uma hierarquia entre os direitos (Caldeira, 1991).

Como é possível perceber, as qualificações que os participantes atribuem a si mesmos e aos adolescentes são da ordem da moralidade, "coladas" em si e nos outros como identidades. Isso mostra que os jogos de verdade envolvidos na relação dos sujeitos com a norma transformam-na em suas próprias verdades, de maneira a regular as suas condutas (Prado Filho, 2010). A composição destas "verdades" resulta na produção política da subjetividade, e, como afirma o autor, "convém destacar o caráter de bricolagem dessa produção, envolvendo variadas 'colagens': desde a separação do indivíduo, a colagem das várias identidades - civil, moral, familiar, econômico/produtiva, também psicológica - além da chancela da normalidade" (Prado Filho, 2010, p. 189).

Perante a legitimação desta "hierarquia moral" (Souza, 2010), a vida destes jovens "infratores" são consideradas "vidas matáveis", vidas que nada valem, tal como o enigma do homo sacer, figura sagrada do Direito Romano arcaico que, pelo cometimento de um delito tornava-se impura e, portanto, seu corpo não poderia ser oferecido em sacrifício; figura ainda cuja morte é impune e seu autor não é considerado assassino - vida excluída, assim, tanto do terreno dos homens quanto dos deuses (Agamben, 2002).

Tambémaquestão dodiscernimento-relacionada à inimputabilidade penal -, aparato sobre o qual muitas vezes repousou a determinação da responsabilidade penal de crianças e adolescentes no Brasil ${ }^{9}$, está ligada à exigência da constatação da culpabilidade a ser manifestada pelo sujeito e comprovada por saberes técnicos (Oliveira, 2002). Os enunciados na página acerca da questão do discernimento o abordam como uma forma de proteção desmedida destinada aos adolescentes: "São de menor (sic) e indefesos, não sabem o que estão fazendo, dizem os defensores. tiram a vida de muitos homens de bens" (grifo nosso) - "equívoco ortográfico" bastante coerente com a realidade segundo denuncia Oliveira (1999, p. 02), pois o combate ao "mal-estar" e a reivindicação pelo "bem-comum", muitas vezes, torna-se uma "abstração necessária para garantia dos bens em particular", posto que se encontram em uma sociedade de consumo fundada na propriedade privada.

Problematiza-se o fato de que, além de o foco atribuído ao discernimento ocultar o verdadeiro debate sobre a quem se destina a redução da maioridade penal e se a punição é a melhor saída frente à questão da criminalidade/criminalização juvenil, a inserção do discurso do discernimento imuniza a problematização de que, como aponta Sandrini (2009), a própria penalização torna-se fator fundamental para inserção na criminalidade. Isto porque não requer uma reformulação de identidades, mas, ao contrário, a impregnação destas no corpo do sujeito: como afirma Foucault (2009), a categorização do sujeito como criminoso através da sua inserção no sistema penal, marca sua individualidade e fixa identidades, impondo uma verdade que liga o sujeito a si mesmo e ao reconhecimento dos outros como tal.

Estes adolescentes, sob a lógica da "meritocracia" (Souza, 2010), também são identificados pelas "escolhas" que fazem, de modo a comprovar suas condições desviantes, como se percebe nas falas dos participantes: "Abriu dez carros, lamento nunca ter aberto um livro". Este modo de conceber a realidade instituído pelo modelo neoliberal, comporta o paradoxo

9. A questão do discernimento entrou e saiu de cena inúmeras vezes como critério para responsabilização penal no Brasil com os diferentes códigos criminais. A manutenção da noção de inimputabilidade penal no ECA, instaura uma incongruência, pois tal noção advém do Código Penal de 1940, justamente com o qual o Estatuto buscou romper ao excluir crianças e adolescentes deste código e criar uma legislação especial que a eles se volte como sujeitos que se encontram em “condição peculiar de desenvolvimento" (Sandrini, 2009). 
de eleger a liberdade do homem como seu principal valor, ao mesmo tempo em que o ato de escolha está enredado em uma "política de subjetividade homogeneizadora e a uma ordem econômico-política excludente, onde as possibilidades são apenas virtuais e imagéticas" (Sawaia, 1999, p.19). Desta maneira, ocorre uma legitimação e naturalização da desigualdade social como uma condição dada a priori, amenizando o impacto de sua violência.

Não se trata de desconsiderar a escolha e admitir a constituição do sujeito como mero resultado do meio, tampouco inerte aos jogos de verdade que operam na sociedade, mas de propor a ruptura com a ideologia do desempenho empregada no processo de acumulação capital (Souza, 2010). Atenta-se para o fato de que, numa sociedade em que para todos operam as mesmas lógicas do consumo, em que o capital penetra por todos os fluxos determinando não só o consumo de bens em si, mas, sobretudo, o consumo de formas de vida a adesão de jovens pelo tráfico, por exemplo, como explica Zaluar (1994), também é sustentada pela possibilidade de dispor de performances corporais e narrativas que possam lhes atribuir status e reconhecimento.

Na página circulam fotos reais de meninos negros e pobres ostentando armas imensas ou fazendo poses em que são ressaltadas as posturas de afronta ou desafiadoras, referindo à suposta ausência de vestígios de submissão ou da pobreza sobre a qual se possa ter piedade e compaixão. Estes elementos parecem também ser ingredientes na crença sobre o poder que supostamente lhes é conferido, equivalente à punição que lhes cabe.

É possível constatar o abismo que se funda entre o ideário construído e fixado sobre estes jovens e as nuances de suas realidades vividas que comportam várias dimensões não capturadas nos discursos dos participantes da página. Ao serem estes jovens banidos das categorias de sujeitos, cidadãos ou seres humanos, são invalidadas ou ridicularizadas as dimensões que possam aproximá-los a categorias humanizadoras: "As 3 mentiras mais utilizadas pelos 'Vidas Lokas': 1 - Sou trabaiadô senhô; 2- Eu sou apenas usuário; 3 - Eu corri por que eu tava com medo senhô (sic)". Tais justificativas parecem não ser permitidas àqueles que são inteligíveis apenas como alego- rias do mal, e, deste modo, indicam os códigos de relacionamento legitimados para com sujeitos assim concebidos, como a violência, o sarcasmo e a deslegitimação do sofrimento, deixando claro a necessidade de repulsa a qualquer indício de humanidade para manter homogeneamente assimilável o lugar a eles destinado (Zaluar, 1994).

É também importante demarcar que a "volúpia punitiva" (Singer, 1998) endereçada aos corpos jovens parece operar de maneira mais enérgica do que se estes fossem adultos. Isto diz respeito ao lugar que a sociedade destina aos sujeitos que atravessam o período de transição do corpo infantil para o corpo adulto, em que, por terem sido cimentadas hegemonias discursivas de uma representação cultural da adolescência/juventude como período de constituição identitária e de rebeldia, estes sujeitos são vistos com apreensão e como seres que necessitam de contenção e domesticação de seus impulsos (César, 2008).

O modelo científico da Psicologia do início do século XX foi coadjuvante no processo de construção deste termo e de uma dada compreensão sobre a "adolescência" tendo, por meio de um viés cartesiano e racional, apreendido o "adolescente" como um ser incompleto que supostamente atingiria a completude quando adulto, atribuindo-se a ele qualidades específicas, estáveis e generalizadas (César, 2008). Interessante notar que, concomitante à construção da adolescência como um "problema", coexiste a "teenagização' da cultura ocidental” (Kehl, 2004, p. 50, grifo da autora) como um modo de ser jovem em uma sociedade hedônica, individualista e imediatista, que cultua a novidade incessante. Deste modo, a conduta transgressora a qual é convocada aos adolescentes encontra-se no intermédio ambivalente entre a idealização e temor, pois, ao mesmo tempo em que à adolescência designa-se a materialização dos "privilégios" de uma sociedade capitalista e moderna, ela representa a possibilidade de ameaçá-los (Sandrini, 2009).

Não pede paz, só quando tem defuntos no jardim ${ }^{10}$

$\mathrm{Na}$ página pesquisada, a compreensão do contexto concernente à criminalização dos jovens

10. Parte da letra musical "O show começa agora" do grupo de rap Facção Central que aborda o clamor por paz das classes "abastadas" apenas quando se trata dos "seus": "protesto é só quando boy morre". A letra propõe que eles, que são da periferia, são apenas vistos e lembrados como "problemas" quando infringem a lei e incomodam: "eu só sou um problema se atravesso o vidro cato a bolsa e o toca CD e atiro no ouvido". 
concentra-se principalmente na concepção de instituições de controle social formais - sistema judiciário, carcerário e policial - e informais - escola, família, meios de comunicação e religião como frouxas, obsoletas e ineficazes, supostamente mantidas por uma sociedade protetora e permissiva, que se constituem como entraves culminantes na impunidade. Neste ínterim, a página apresenta como saídas frente a este contexto: o endurecimento destas instituições de controle formais e informais; fazer justiça com as próprias mãos; mudanças governamentais e, ainda, a realização de avaliações do discernimento.

Considera-se, na página, que a aplicação ou a falta de castigo físico e da educação pelo medo são, no que concerne ao âmbito microssocial familiar, os principais fatores que produzem "bons" ou "maus" cidadãos: "Se você se lembra disso: chinelada, cintada e a doída vara de goiabeira que nunca quebra...Você não falava palavrão Aprendeu a respeitar os mais velhos Se cuidava pra não fazer algo de errado Provavelmente hoje é um bom cidadão (sic)". Confunde-se comumente, como propõe Amorim (2013), a estipulação de limites com a imposição de punições e castigos: segundo a autora, os limites podem indicar cuidado e respeito, manifestando o reconhecimento da existência do outro e do vínculo afetivo para com este; a punição, no entanto, muito próxima está da anulação dos sujeitos.

Em relação a estas compreensões, há que se considerar as complexas transformações nas formas de sociabilidade que ocorreram ao longo do século $\mathrm{XX}$, em que a diminuição da capacidade de autorregulação da sociedade informal e da resolução de seus conflitos (Castel, 1998), passaram a exigir intervenções estatais para garantia de proteção. É nesta trajetória que a sociedade contemporânea consolida sua forma habitual de resolução de conflitos marcada pelo que se denomina por "judicialização" ou "judiciarização", em que os conflitos sociais são traduzidos em termos jurídicos, reduzindo a amplitude dos conflitos em um "equivalente geral (um tipo penal, por exemplo) e a partir dele definir uma modalidade de prova ou de enfrentamento legal a ser seguida" (Rifiotis, 2012, p. 74), atribuindo-se a esferas jurídicas a resolução de impasses sociais.

Percebe-se ainda que atenuação dos termos na legislação constitui-se como motivo para os participantes da página pesquisada conceberem a "sociedade" e as leis como protetoras e permissivas: os adolescentes "impunes e protegidos", os demais, vitimizados, portanto, estão autorizados fazer "justiça com as próprias mãos". Agentes socioeducativos, agentes de segurança pública, entre outros integrantes do percurso penalizador, também parecem se autorizar a fazer "justiça com as próprias mãos": segundo dados do Conselho Nacional de Justiça (2012), há graves violações de direitos como maus-tratos, torturas, ameaças à integridade física, negligências ao atendimento de saúde e violências psicológicas por parte destes agentes, que não cessam mesmo com o controle e fiscalização realizada pelo Sistema Nacional de Atendimento Socioeducativo (SINASE).

Em termos de taxas e estatísticas sobre penalizações, o discurso da "impunidade" de adolescentes autores de ato infracional é infundado. Sendo a privação de liberdade a principal punição a que clama a página, os dados da Secretaria Especial dos Direitos Humanos de 2010 mostram que há 12.041 adolescentes cumprindo medida de internação, 3.934 em internação provisória, e 1.728 em semiliberdade, sobrepondo-se a privação de liberdade como principal medida, mesmo com déficit de vagas, fato que leva inclusive a medidas "alternativas" como prisões em delegacias e presídios adultos (Brasil, 2010). A prática compulsória da medida de internação como "carro-chefe" das medidas socioeducativas, ignora os princípios expostos no Estatuto da Criança e do Adolescente acerca desta medida, a ser considerada como o último recurso possível.

Ao discutir-se sobre "impunidade", considera-se ainda que, conforme Adorno e Pasinato (2010), as taxas de impunidade no Brasil mostram-se significativamente elevadas para crimes que apresentam violação grave aos direitos humanos como homicídios cometidos pela polícia, patrulha privada, grupos de extermínio, esquadrões da morte e demais agentes de segurança, bem como os crimes de "colarinho branco" cometidos por cidadãos de classes médias e altas da sociedade, fatos naturalizados e silenciados. Assim, como se atribuem diferentes valorações aos sujeitos, da mesma forma, há diferentes gradações sobre os tipos de punição ou tipos de violência que são condenadas e aquelas que são consentidas e incentivadas: os crimes de colarinho branco e a corrupção policial abordados na página virtual não possuem o mesmo "tom" de retaliação em relação àqueles cometidos por adolescentes, da mesma forma como repressões e extermínios policiais para eles não são vistas como 
violação dos direitos humanos, mas sim, frente a determinados adolescentes e contextos, como intervenções legítimas de resolução de conflitos.

Retorna-se novamente à noção de "humanidade" e "cidadania" conforme anteriormente dito, como uma questão que marca o lugar concedido a cada "sujeito" na escala valorativa da sociedade para compreender, a partir de Caldeira (1991) o quanto, no Brasil, é marcante a convicção de "homens de bem" se responsabilizarem no combate aos "privilégios de bandidos" como slogan da campanha contra os defensores dos direitos humanos. Segundo Caldeira (1991), a reivindicação pela expansão dos direitos coletivos de minorias aos direitos civis de presidiários no período da redemocratização, como humanização dos presídios e reforma da polícia - sendo apenas um componente do todo reivindicatório da época - configurou-se como a extrapolação do limite do aceitável, disseminando-se a ideia de uma proteção desmedida a pessoas não merecedoras destes direitos. Estes aspectos foram capturados pelos discursos da política institucional da época de forma a criar aversão aos defensores dos direitos humanos, fato que, por sua vez, teve ampla aceitação social.

A ênfase desta correlação de direitos humanos como privilégios para bandidos é um dos principais pilares na sustentação do discurso do recrudescimento penal na página investigada. A recorrente expressão “Tá com dó? Leva pra casa!", como um tipo de jargão utilizado por muitos integrantes, sugere que aqueles que se posicionam contrariamente à redução da maioridade penal - nomeados de "defensores dos direitos humanos" - estariam apiedados daqueles que cometem crimes. Tal expressão constitui-se, portanto, como uma importante síntese que denota claramente esta concepção historicamente construída sobre os direitos humanos conforme apontado por Caldeira (1991), de modo que a identidade de "bandido" atribuída a determinados adolescentes, conforme já explicitado, destitui a noção de humanidade e de cidadania dos mesmos, geralmente balizada pelo critério do merecimento, como complementa este outro clichê: "Direitos humanos para humanos direitos".

A oposição aos direitos humanos como incrementa o discurso que legitima violências de quaisquer ordem para com estes jovens, de modo que o recrudescimento das punições expresso na página não se concentra no propósito desta que seria o favorecimento à redução da maioridade penal - ou ainda a alterações no Estatuto da Criança e do Adolescente sobre ampliação do tempo de internação - mas também se dedica a incentivar a pena de morte, a prisão perpétua, a prática de castigos físicos pelos “justiceiros", pelas "autoridades" familiares, a repressão policial e a violência de agentes socioeducativos. Não há clareza sobre as leis atuais tampouco sobre as condições reais de existência daquelas que gostariam que existissem. Fala-se em reduzir desde os $10 \mathrm{ou}$ até mesmo não ter idade; em extermínio; em fazê-los sofrer perante toda sociedade até a morte; em trabalhos pesados na prisão, sem nenhuma "regalia". São inúmeras as formas de "pagamento" e de fazer "justiças" que explicitam a coexistência no ideário punitivo as noções trazidas por Foucault (2000) tanto das práticas dos suplícios que se aproximam de barbáries, quanto da tecnologia de punição asséptica de economia do corpo.

Como possíveis avaliações do impacto da redução da maioridade penal constam tais falas: “seria melhor em tudoooo!!”; “reduzir salvará vidas"; "a dentista não seria queimada viva, o jovem estagiário de jornalismo não teria levado um tiro na cabeça sem reagir a um assalto, a jovem trabalhadora não seria estuprada dentro de um ônibus, e vários outros casos..."

Da "curtição" do mundo das redes sociais ou do mundo "teen" idealizado em que se pode consumir sem preocupações (Kehl, 2004) ou ainda, do mudo controlado, seguro e livre (Bauman, 2003) partem premissas de que mandar jovens mais cedo para a prisão será fator responsável por extinguir a criminalidade, a violência, a marginalidade e a pobreza, dando continuidade à cultura autoritária (Passetti, 1999), deixando viver as vidas que devem ser vividas e deixando morrer as vidas que podem ser matáveis (Agamben, 2002, itálico nosso).

Se, conforme Passetti (1999) desde o século XVIII já se apontava para a ineficiência da reclusão e, sendo esta uma representação difundida e generalizada na sociedade, o que faz com que discursos que pretendem imputar penas de adultos a adolescentes tenham tanta força em pleno século XXI? Neste sentido, o que à primeira vista se constitui como uma incongruência, já apontava Foucault (2000) que, ao contrário, a instituição prisional trata-se de estratégia de sucesso, pois sendo central no rol dos dispositivos carcerários, a prisão encerra seu verdadeiro objetivo ao delimitar e produzir a delinquência como especificidade ilegal econômica e politicamente utilizável, 
ao "produzir os delinquentes sendo meio aparentemente marginalizado, mas socialmente controlado; produzir o delinquente como sujeito patologizado" (Foucault, 2000, p. 230).

Na garantia da eficácia destes dispositivos disciplinares do encarceramento, estão os saberes científicos médicos e psicológicos a serviço do "exame", que operam por meio da atribuição de causalidade, juízos de normalidade e da predição de seus comportamentos (Foucault, 2000). Não é à toa que o lugar destinado à Psicologia pelos participantes está em dispor de critérios de avaliação para precisar se o sujeito dispõe ou não de discernimento por meio deste saber: "dveria passar por uma avaliação de especialista, psicológa, pra dizer se sabe o que tá fazendo ou não (sic)" sendo esta uma das medidas propostas de enfrentamento da criminalidade. Que saber é este que pode determinar tal verdade?

Concebido como perito da intimidade, do subjetivo, o profissional da Psicologia nos espaços jurídicos é convocado a confeccionar laudos, pareceres e relatórios técnicos que produzam verdades sobre os sujeitos, dispondo de práticas que pouco romperam com os saberes produzidos desde o disciplinar século XIX, pois, ainda que alguns profissionais possam dispor de análise crítica de sua práxis, avaliando-a como instrumento de controle social, muitos não aliam a dimensão política ao seu próprio fazer, adequando-se às demandas institucionais; outros profissionais, porém, tampouco avaliam (Coimbra, Ayres, \& Nascimento, 2010).

Esta convocação ao profissional psicólogo, bem como sua adequação não é infundada, pelo contrário: ao propor enunciados a versar sobre quem é o indivíduo, sua subjetividade - em relação à norma - o saber psicológico conquistou o seu lugar deste modo, menos como ciência e mais como "disciplina da norma”, fato perceptível em suas práticas, segundo Prado Filho (2005). Neste formato, à Psicologia não convém ser concebida como coadjuvante do poder normalizador, mas ela mesma pode atuar como saber normalizador e mantenedor do status quo (Prado Filho, 2005) e, por isso, também é convocada a fazer-se presente nos domínios "re" - reabilitação, ressocialização, reeducação - ilusões que não fazem outra coisa senão mascarar realidades e vidas devastadas por exclusões de toda ordem e que nestes domínios tornam-se alvos de ainda mais prescrições e violências (Batista, 2010).
Dado que no sujeito se objetivam várias formas de exclusão (Sawaia, 2004), quais possibilidades reais se efetivam para aqueles que são postos nestes lugares físicos e simbólicos? Questiona-se ainda, frente a tantas prescrições de violência e repressão destinadas a estes jovens, apresentadas na página virtual pesquisada, que ordem social de "paz e justiça!" é essa pela qual se clama?

\section{Considerações finais}

A partir dos objetivos propostos pela pesquisa, foi possível perceber que os adolescentes que são alvos das propostas da redução da maioridade penal na página de análise são representados exclusivamente por adolescentes negros e pobres, os quais são excluídos das condições de cidadãos, adolescentes e inclusive de seres humanos e incluídos em categorias desqualificadoras tais como "monstros", "menores marginais" e "não humanos". A partir desta hierarquia de valoração moral dos sujeitos, delimita-se a seletividade tanto da punição quanto do merecimento de direitos e garantias.

Os participantes da página pesquisada compreendem que o contexto que propicia a criminalidade são as instituições sociais de controle formais e informais insuficientemente severas e punitivas, compondo uma sociedade protetiva e permissiva, responsável pela produção da impunidade. Consolida-se assim uma rigorosa crítica endereçada aos defensores dos direitos humanos que não protegem os "homens de bem" e, com isso, os participantes propõem o recrudescimento destas instituições e a eliminação de sujeitos considerados indesejáveis.

A página virtual pesquisada parece servir apenas como palco das expurgações no combate ao mal-estar localizado sobre um determinado grupo de sujeitos, não havendo discussões efetivas sobre as temáticas apresentadas - tampouco sobre a própria redução da maioridade penal. É preciso, portanto, apontar os limites deste estudo de modo a ressaltar que se trata de um recorte, e que, portanto, o conteúdo da página analisada não permite expressar as concepções socialmente vigentes acerca dos debates favoráveis à redução da maioridade penal, assim como reafirmar as limitações perante as condições em que emergem tais discursos - as redes sociais - que, conforme afirmado anteriormente, possuem especificidades que não podem ser desconsideradas. No entanto, são 
também estes enunciados da virtualidade, caracterizados como informais, descomprometidos com a criticidade e menos polidos (Rudiger, 2002), que interessam para a pesquisa científica.

Importante destacar ainda que tais discursos apresentados pelos sujeitos integrantes desta página virtual não estão isolados e, portanto, tampouco se deve transpor o retrato do mal a estes seres ávidos por punição: eles estão amparados em um contexto altamente incitador da obsessão punitiva sobre populações jovens e pobres, orquestrado por ideologias neoliberais produtoras da desigualdade que apresentam como solução ao medo e insegurança instaurados, políticas criminais de limpeza urbana cada vez mais intolerantes e repressivas e que possuem a criminalização da pobreza como sua principal estratégia. Amparam-se também em ideologias culturais que concebem jovens e adolescentes como "problemas", e que, portanto, necessitam de contenção. Ancoram-se ainda em formas de resoluções de conflito cristalizadas na adversariedade e na punição severa.

\section{Referências}

Agamben, G. (2002). O poder soberano e a vida nua I (H. Burigo, trad.). Belo Horizonte, MG: Editora UFMG.

Adorno, S., \& Pasinato, W. (2010). Violência e impunidade penal: da criminalidade detectada à criminalidade investigada. Dilemas, 3(7): 51-84. Recuperado de http://revistadil.dominiotemporario.com/doc/ Dilemas7Art3.pdf

Amorim, S. (2013). Redução da maioridade penal (Grandes Temas do Conhecimento. Psicologia, no 6). São Paulo, SP: Mythos.

Andrade, V. R. P (2003). Sistema penal máximo x cidadania mínima. Porto Alegre, RS: Livraria do Advogado.

Aulete Digital. Dicionário da língua portuguesa. Rio de Janeiro, RJ: Lexicon. Disponível em: www.aulete.com.br. Acesso em 12/09/2015.

Batista, V. M. (2010). Adeus às ilusões "re". In C. M. B. Coimbra, L. S. M. Ayres, M. L. Nascimento (Org.), Pivetes: encontros entre a psicologia e o judiciário (pp. 195-199). Curitiba, PR: Juruá.

Bauman, Z. (2003). Comunidade: a busca por segurança no mundo atual. Rio de Janeiro, RJ: Jorge Zahar.

Brasil (2010). Secretaria Especial dos Direitos Humanos. Subsecretaria de Promoção dos Direitos da Criança e do Adolescente. Apresentação do levantamento nacio-
A maquinaria punitiva é extensa e os participantes de páginas virtuais favoráveis e demais adeptos da redução da maioridade penal, bem como a própria medida, são apenas uma ínfima parte de todo este movimento. A grande questão que se coloca é que a punição, resplandecendo como a solução para todos os males, seja nas relações familiares, escolares ou jurídicas, ofusca a complexa problemática na qual tais discursos estão enredados. E, sobretudo, o fato de que as medidas de recrudescimento da punição apresentadas, em si se retroalimentam e geram aquilo que combatem, pois criam terrenos estéreis para novas possibilidades, tanto para os sujeitos punidos quanto para os punidores.

Perante tais apontamentos, é possível avaliar que, frente aos discursos sobre a redução da maioridade penal, cabe à Psicologia - enquanto ciência e profissão - posicionar-se de modo a subverter às convocações em prol da manutenção da cultura punitiva e autoritária que visa o engessamento de identidades, normalidades e moralidades, tanto no âmbito das políticas institucionais, quanto nas micropolíticas das relações sociais.

nal do atendimento socioeducativo ao adolescente em conflito com a lei. Brasília, DF: o autor.

Caldeira, T. P. R. (1991). "Direitos humanos ou 'privilégios de bandidos'?” Desventuras da democratização brasileira. Novos Estudos, (30), 162-174. Recuperado de: http://novosestudos.uol.com.br/v1/files/uploads/contents/64/20080624_direitos_humanos_ou_ privilegios_de_bandidos.pdf

Castel, R. (1998). As metamorfoses da questão social: uma crônica do salário. Petrópolis, RJ: Vozes.

César, M. R. A. (2008). A invenção da adolescência no discurso psicopedagógico. São Paulo, SP: Editora UNESP.

Chauí, M. (1980). O que é ideologia? (Coleção Primeiros Passos). São Paulo, SP: Brasiliense.

Ciriaco, D. (2012). Brasil foi o país com maior número de novos usuários do Facebook em 2012. Recuperado de http://www.tecmundo.com.br/facebook/ 35709-brasil-foi-o-pais-com-maior-numero-denovos-usuarios-do-facebook-em-2012.htm

Coimbra, C. M. B., Ayres, L. S. M., \& Nascimento, M. L. (2010). Cartografias jurídicas: discursos e práticas psi no Judiciário. In C. M. B. Coimbra, L. S. M., \& Ayres, M. L. Nascimento (Orgs.), Pivetes: encontros entre a psicologia e o judiciário. Curitiba, PR: Juruá. 
Confederação Nacional dos Transportes (2013). Pesquisa CNT/DMA: relatório síntese. Recuperado de http://www.cnt.org.br/Imagens\%20CNT/PDFs\%20 CNT/Pesquisa_CNT_MDA_Relatorio\%20SINTESE\%20-\%20CNT\%20JUNHO2013\%20-\%20R113\%20 -\%20FINAL.pdf

Conselho Federal de Psicologia (2013). Notícias: redução da maioridade penal. Recuperado de http:// site.cfp.org.br/reducao-da-maioridade-penal/

Conselho Nacional de Justiça (2012). Panorama nacional: a execução de medidas socioeducativas de internação. Programa Justiça ao Jovem. Recuperado de http://www.cnj.jus.br

Datafolha - Instituto de Pesquisas (2013). 93\% dos paulistanos apoiam redução da maioridade penal. Recuperado de http://datafolha.folha.com.br

Foucault, M. (2000). Vigiar e punir: história do nascimento das prisões. Petrópolis, RJ:Vozes. (2009). O sujeito e o poder. In P. Rabinow, \& H. Dreyfus. Michel Foucault: uma trajetória filosófica (para além do estruturalismo e da hermenêutica (pp. 231-249). Rio de Janeiro, RJ: Forense Universitária.

Fundo das Nações Unidas para a Infância - Unicef. (2007). Porque dizer não à redução da maioridade penal. Recuperado de http://www.crianca.caop. mp.pr.gov.br

Kehl, M. R. (2004). Juventude como sintoma da cultura. In R. E.Novaes, \& P. Vannuchi, Juventude e sociedade: trabalho, educação, cultura e participação (pp. 89-113). São Paulo, S: Fundação Perseu Abramo. Lyon, D. (1997). A sociabilidade do ciberespaço: controvérsias sobre relações mediadas por computador. In B. Loader, A política do ciberespaço (pp. 56-74). Silves: Instituto Piaget.

Minayo, M. C. S. (1994). Pesquisa social: teoria, método e criatividade. Petrópolis, RJ: Vozes.

Minayo, M., \& Deslandes, S. (2002). Caminhos do pensamento: epistemologia e método. Rio de Janeiro, RJ: Fiocruz.

Oliveira, A.L. (2002). Redução da idade penal: um velho sonho para jovens sonhadores. In V. R. Andrade (Org.), Verso e reverso do controle penal: (des) aprisionando a sociedade da cultura punitiva: homenagem a Alessandro Baratta (Vol. 2, pp. 195-220). Florianópolis: Fundação Boiteux.
Oliveira, S. M. (1999). A moral reformadora e a prisão de mentalidades. Perspectiva, 13(4), 75-81. doi:10.1590/S0102-88391999000400008

Passetti, E. (1999). Violentados. São Paulo, SP: Imaginário.

Prado Filho, K. (2005). Para uma arqueologia da psicologia (ou: para pensar uma psicologia em outras bases). In N. Guareschi, \& S. Hüning (Orgs.), Foucault e a psicologia (pp. 73-91). Porto Alegre, RS: Abrapso Sul. (2010). Uma genealogia das práticas de normalização nas sociedades ocidentais modernas. In Caponi, S.; Verdi, M; Brzozowski, F. S., \& Hellmann, F. Medicalização da vida: etica, saúde pública e indústria farmacêutica (pp. 183-191). Florianópolis, SC: EdUNISUL.

Preteat, J., Silva, R. S, Triska, R., \& Schulenburg, H. (2012). Compreendendo a relação entre a gestalt e o design da informação na apresentação das ações curtir, comentar e compartilhar no facebook. Revista Travessias, 6(3). Recuperado de: http://e-revista. unioeste.br/index.php/travessias/article/view/7197

Rifiotis, T. (2012). Direitos humanos: sujeitos de direitos e direitos do sujeito. In T. Rifiotis, \& D. Vieira (Orgs.), Um olhar antropológico sobre a violência e justiça (pp. 13-26). Florianópolis, SC: Editora da UFSC.

Rudiger, F. (2002). Elementos para a crítica da cibercultura. São Paulo, SP: Hacker.

Sandrini, P. (2009). O controle social da adolescência brasileira: gênese e sentidos do Estatuto da Criança e do Adolescente. (Tese de Doutorado). Universidade Federal de Santa Catarina, Florianópolis, SC.

Sawaia, B. B. (1999). Comunidade como ética e estética da existência: uma reflexão mediada pelo conceito de identidade. Psykhe, 8(1), 19-25. Recuperado de: http://www.psykhe.cl/index.php/psykhe/article/view/384 (2004). O sofrimento ético-político como categoria de análise da dialética exclusão/inclusão. In: B. B. Bader (Org.), As artimanhas da exclusão: análise psicossocial e ética da desigualdade social (pp. 7-15). Petróplis, RJ: Vozes.

Segata, J. (2012). A "vítima" é a parte mais frágil da relação? A antropologia e a violência conjugal. In T. Rifiotis, \& D. Vieira (Orgs.), Um olhar antropológico sobre a violência e justiça (pp. 79-98). Florianópolis, SC: Editora da UFSC. 
Singer, H. (1998). Direitos humanos e volúpia punitiva. Revista USP, (37), 10-19. doi:10.11606/issn.2316-9036.v0i37p10-19

Souza, J. O avesso da democracia na produção da subcidadania (2010). In Democracia e subjetividade: $a$ produção socialdos sujeitos democráticos (pp.31-40). Brasília, DF : Conselho Federal de Psicologia.

Wacquant, L. (2001). As prisões da miséria. Rio de Janeiro: Jorge Zahar.

Waiselfisz, J. J. (2012). Mapa da violência 2012: crianças e adolescentes do Brasil. Recuperado de http:// www.mapadaviolencia.org.br

Zaluar, A. (1994). Condomínio do diabo. Rio de Janeiro: Editora Revan.

\section{Heloísa Petry}

Mestranda em Psicologia pela Universidade Federal de Santa Catarina.

E-mail: heloisa.petry@posgrad.ufsc.br
Deise Maria do Nascimento

Doutora em Psicologia pela Universidade Federal de Santa Catarina, Florianópolis - SC. Brasil. Docente da Universidade do Sul de Santa Catarina, Florianópolis - SC. Brasil.

E-mail: deisemn@uol.com.br

Endereço para envio de correspondência: Endereço para envio de correspondência: Rua Urbano Agostinho, 166. Colônia Santana. CEP: 88123-110. São José - SC. Brasil.

Recebido: $13 / 11 / 2014$

Aprovado: 09/12/2015

Received: $11 / 13 / 2014$

Approved: 12/09/2015

Recibido: $13 / 11 / 2014$

Aceptado: 12/09/2015

Como citar: Petry, H., \& Nascimento, D. M. (2016). “Tá com dó? Leva pra casa!” Análise dos discursos favoráveis à redução da maioridade penal em rede social. Psicologia: Ciência e Profissão, 36(2): 426-438. doi:10.1590/1982-3703001562014

How to cite: Petry, H., \& Nascimento, D. M. (2016). “Do you feel sorry for him? Then take him into your home!” analysis of speeches in favor of reducing the legal age for criminal responsibility in a social network. Psicologia: Ciência e Profissão, 36(2): 426-438. doi:10.1590/1982-3703001562014

Cómo citar: Petry, H., \& Nascimento, D. M. (2016). “¿Sientes pena por él? ¡Pues llévatelo para tu casa!” análisis de discursos favorables a la reducción de la mayoría de edad penal en una red social. Psicologia: Ciência e Profissão, 36(2): 426-438. doi:10.1590/1982-3703001562014 